\title{
HISTÓRIA DA ARTE PARA CRIANÇAS: UM COMENTÁRIO BIBLIOGRÁFICO
}

\author{
Angela Brandão*
}

De que serve um livro sem palavras nem imagensं

Lewis Carol

Percorrer as estantes reservadas aos livros infanto-juvenis em livrarias e bibliotecas; ou mesmo as prateleiras de histórias em quadrinhos e revistas de passatempos das bancas de jornal; ou uma tarde perdida entre desenhos animados são experiências que dizem, de modo redundante, quão pouca qualidade de imagens é oferecida aos olhos infantis. As crianças estariam definitivamente condenadas, desde os ursinhos dos papéis de parede de seus quartos, a conviver com imagens de mau gosto em abundância.

Sempre me perguntei por que as obras de arte, ao menos aquelas consagradas como valores universais pela história, demoravam tanto a chegar aos olhos das crianças. Lembro-me, perfeitamente, de meu primeiro contato com reproduções de obras de arte em um livro: as ilustrações da Bíblia Sagrada. Muito mais tarde descobri que aquela não tinha sido uma experiência isolada, e ainda mais tarde, descobri que justamente naqueles anos a indústria gráfica brasileira dava seu salto mais significativo em direção à impressão de qualidade de imagens em cores. Em 1965, a Editora Abril lançava esta sua "Bíblia Sagrada Ilustrada" com obras de arte, em fascículos, constituindo um fenômeno editorial de mais de cento e cinqüenta mil exemplares vendidos. Assim também naqueles anos, a série dos "Gênios da Pintura" fora um marco na reprodução de obras de arte no Brasil, sempre pela Abril'1.

Mesmo que esses livros não tivessem sido dirigidos ao público infantil, determinaram uma espécie de popularização e de possibilidade de visualizar as obras de arte disseminada nas bibliotecas de escolas e nas casas de classe média. A Editora Lello \& Irmãos do Porto, nas primeiras décadas do século XX, depois de sua fascinante enciclopédia ricamente ilustrada,

\footnotetext{
* Professora de História da Arte, História das Artes Gráficas e História do Mobiliário no Departamento de Desenho Industrial da Universidade Tecnológica Federal do Paraná. Doutora em História da Arte pela Universidade de Granada, Espanha.

1 PAUlA, Ademar A. de e CARRAMILLO NETO, Mário. Artes Gráficas no Brasil. Registros: 17461941 e GORDINHO, Margarida Cintra et al. Gráfica: Arte e Indústria no Brasil: 180 anos de bistória. São Paulo: Bandeirante, 1991.
} 
Tesouro da Juventude, dedicava também a um público juvenil uma Enciclopédia pela Imagem ${ }^{2}$. O material provinha de uma edição francesa da Hachette. A partir de temas como Mitologia ou a História Sagrada, editados em fascículos, as obras de arte, em reproduções sem cores, apresentavam-se aos olhos juvenis como ilustrações do texto explicativo. A obra de arte estava ali apenas para confirmar as afirmações do texto. "A imagem é soberana: vivemos no século da fotografia (...) é a imagem que primeiro nos informa (...) as novidades da arte. O texto esse vem depois”. Embora a iniciativa trouxesse esta indicação em todas as contracapas, no corpo do texto as coisas estavam invertidas. É também essa mesma inversão característica de grande parte dos livros didáticos de história - a obra de arte ilustra uma passagem histórica, pouco mais.

Ao contrário do que acontece em outros países, a história da arte não compõe oficialmente, no Brasil, o quadro de disciplinas ofertadas no ensino fundamental e médio. Não há, portanto, de modo geral, um esforço sistemático de apresentação de um percurso, o mais completo possível, da arte no tempo, nem tampouco uma trajetória da arte brasileira. Obras e artistas são apresentados de modo fragmentado, muitas vezes diluídos em outras disciplinas como artes, história ou língua portuguesa. Inexiste, raras exceções, a compreensão de que a história da arte seja uma matéria com métodos específicos de pesquisa e ensino. Assim, professores e pais lançam mão de livros paradidáticos que tratem de temas da história da arte.

Observemos algumas publicações, sobretudo em torno dos anos 1990, que se dedicavam a levar as obras de arte de diferentes períodos da história para um público infantil. Em parte, essas edições apresentavam as obras não necessariamente num referencial histórico-artístico, mas dirigidas a uma compreensão de caráter técnico. Rod Holt, em Pintura a Óleo: Estojo de Trabalho, contribuía com um livro voltado especificamente à criação do artista, sem nenhuma proposta de História da Arte. No entanto, merecia atenção porque apresentava noções técnicas também importantes a um suposto pequeno historiador da arte como: equipamentos e materiais, técnicas de pintura, cor, tema e composição, perspectiva, além de uma definição dos gêneros da pintura (paisagem, natureza morta, retrato) ${ }^{3}$.

Da mesma maneira, com uma orientação de caráter mais técnico que histórico, o livro Uma iniciação interativa às artes plásticas, apresentava

\footnotetext{
${ }^{2}$ Encyclopedia pela Imagem. Porto: Lello \& Irmãos, s.d.

${ }^{3}$ HOLT, Rod. Pintura a Óleo: Estojo de Trabalho. Blumenau, Eko, 1997.
} 
obras do passado aos olhos infantis. Aqui são analisadas sessenta obras de arte conhecidas, voltando-se especialmente às técnicas e materiais utilizados pelos artistas, explicando como se produziram estas obras de arte exemplares. Algumas são apresentadas em cartelas que podem ser manipuladas pelo leitor. Atrás delas se lêem informações a respeito. São tratados temas como a perspectiva, a ilusão tridimensional na pintura (incluindo um óculos 3D). Como a preocupação dos autores é passar à criança sobretudo informações sobre a arte enquanto técnica - e não com enfoque historiográfico - os temas são: luz, cores, movimento, composição, motivo, estilo. É bastante interessante o livro de atividades que o acompanha ${ }^{4}$.

Parece ser essa também a escolha de Uma Catedral Medieval. Este livro está mais preocupado em tratar dos sistemas construtivos das catedrais góticas, trazendo desenhos e textos explicativos sobre todo o processo de elevação destes imensos edifícios. Somente no capítulo Visões do Paraíso procura falar sobre o significado destas obras em seu tempo, propondo, assim, uma reflexão sobre a arquitetura gótica. São também interessantes as Curiosidades sobre Catedrais e Estilos Arquitetônicos e o Glossário, que ajudam a criança a se familiarizar com termos de arquitetura, além de aprender a identificar certos elementos dos estilos arquitetônicos ${ }^{5}$.

Poderíamos entender entre os livros que trazem elementos mais técnicos a respeito da arte a pequenos leitores, também a coleção As Origens do Saber. Além de títulos como A Criação da Pintura, O Trabalho dos Escultores e A Música dos Instrumentos; Era uma vez o cinema, um livro visualmente muito atrativo, trata da origem da sétima arte, sua invenção a partir da lanterna mágica e do praxinoscópio, das primeiras sessões a Charles Chaplin, o início do cinema falado, o cinema como espetáculo hollywoodiano, a montagem dos filmes, as cores, o neo-realismo italiano e a nouvelle vague, etc. A série tem também um caráter lúdico, pois traz adesivos que a criança pode inserir no livro ${ }^{6}$.

Aliás, são bastante raros, salvo os achados em lojas de museus, jogos e brinquedos inspirados em temas artísticos. Quebra-cabeças somente

${ }^{4}$ VAN DER MEER, Ron e WHITFORD, Frank. Uma Iniciação Interativa às Artes Plásticas. No Mundo da Arte.

${ }^{5}$ JAMES, John e MACDONALD, Fiona. Uma Catedral Medieval. São Paulo: Massole, 1993. Coleção Fique por dentro da História.

${ }^{6}$ Era uma vez. o cinema. São Paulo: Melhoramentos, s/d. 
aqueles com mais de mil peças, portanto passatempo para maiores. Desta forma, alguns livros dedicam à história da arte um sentido lúdico, mais do que explicativo ou didático propriamente. É o caso de A arte de Leonardo e Giotto pintor de paredes, ambos de Sylvie Girardet. Esta coleção, Por dentro da arte possui ainda outros títulos sobre Pablo Picasso e Marc Chagall. É uma espécie de desconstrução lúdica de algumas obras. Traz uma introdução sobre a importância da obra do artista tratado, sua biografia facilitada, um jogo para inserir a criança no período em que o artista viveu e uma série de atividades que, a partir de fragmentos das obras, ajudam a criança a observá-la com atenção identificando estes fragmentos no contexto da obra. Constitui-se num treinamento do olhar para detalhes e para a estrutura compositiva das cenas. Apesar deste caráter fragmentário que incide sobre a análise das obras, a série não deixa de ser um bom recurso didático e uma proposta lúdica de iniciação ao universo das artes ${ }^{7}$.

Para a criança brincar com arte: o prazer de explorar belas pinturas, com belíssimas reproduções (impresso na Itália), apresenta para crianças de pouca idade, sem preocupação cronológica ou estilística, obras em que os pequenos possam olhar e se divertir. Há uma ordem temática: a representação na arte em diversos estilos e épocas da casa, das expressões humanas, dos animais, etc. que sugere brincadeiras e atividades em grupo ${ }^{8}$.

Embora até aqui tenhamos falado de livros que se reservam a aproximar a arte das crianças, cumprem também, mesmo que brevemente, uma forma de introduzir elementos de história da arte. Mas há, por outro lado, aqueles que diretamente enfocam a arte em seu aspecto histórico, entre os quais consideramos os livros de história geral da arte para crianças. Não são muitos os exemplos. No início dos anos 1980 propôs-se uma História da Arte para Crianças. Os personagens Marcelo e Daniela preparam-se para uma viagem à Europa, com a orientação e os livros da biblioteca do tio Emílio. Nesta iniciação, o tio vai apresentado às crianças o mundo da arte desde a Pré-História até os anos sessenta (pop e op arte). Alguns períodos são relacionados com a arte brasileira. As dúvidas dos personagens abrem discussões interessantes sobre a percepção da arte por

\footnotetext{
${ }^{7}$ GIRARDET, Sylvie. et allii. $A$ arte de Leonardo. São Paulo: Cia das Letrinhas, 1997. . Giotto pintor de paredes. São Paulo: Cia das Letrinhas, 1997.

${ }^{8}$ MICKELETHWAIT, Lucy. Para a criança brincar com arte. O prazer de explorar belas pinturas. São Paulo: Ática, 1997.
} 
parte das crianças. Importante dizer que são também tratados temas da arte oriental. As reproduções, no entanto, não são muito boas? .

Compreender a Arte apresenta do Renascimento à Arte pop, em cada capítulo, obras representativas do período, em reproduções não muito boas, mas com ótimos comentários sobre o que se vê, como uma orientação ao olhar da criança, além de explicações sobre as técnicas artísticas e compositivas. A linguagem talvez seja um pouco difícil, mas vale a pena o esforço de trabalhar, junto às crianças, com um texto deste nível ${ }^{10}$.

$O$ texto de Robert Cumming, Para entender a arte, não especificamente dirigido à leitura infantil, é bastante erudito, mais adequado talvez a adultos leigos. Não deixa de ser, no entanto, um exemplo metodológico interessante de como explicar o significado - inconografia e iconologia - dos elementos que compõem determinadas obras de arte. As obras são apresentadas em ordem cronológica, do primeiro Renascimento a Picasso. Cada reprodução toma duas páginas inteiras e, através de setas apontadas aos segmentos da obra, são inseridos pequenos textos explicativos. Além disso, há sempre dois pequenos quadros que trazem uma resumida biografia do autor da obra e uma resumida explicação do movimento ou do estilo artístico correspondente ${ }^{11}$.

Entre as obras de caráter geral de história da arte para crianças, podemos inserir aquelas que apresentam uma história da arte brasileira de modo mais ou menos completo. Marilyn Diggs Mange, mesma autora de Santos para criança por crianças e Uma pequena história da pintura através dos quadros do MASP, da editora do MASP, publicou Arte Brasileira para Crianças, onde escolhe como guia um grão de café saído do quadro de Portinari e que atravessa o tempo desde a arte brasileira antes do descobrimento, passando pela arte colonial, pelo Brasil holandês, pela arte barroca, arte do século XIX, Belle-Époque, Modernismo, até chegar na arte brasileira após 1950. O texto é bastante didático, mas infelizmente as reproduções das obras são muito ruins, o que torna o livro pouco atrativo para as crianças ${ }^{12}$.

9 FIGUEIREDO, Lenita Miranda de. História da Arte para Crianças. São Paulo: Pioneira, 1982.

${ }^{10}$ JANUSZCZAK, Waldemar e McCLEERY, Jenny. Compreender a Arte. Lisboa/São Paulo: Verbo Juvenil, 1984.

${ }_{11}$ CUMMING, Robert. Para entender a arte. São Paulo: Ática, 1996.

12 MANGE, Marilyn Diggs. Arte Brasileira para Crianças. São Paulo: Martins Fontes, 1996. 
Todo o contrário, a coleção de cinco volumes Arte Brasileira, publicada em 2006 pela Companhia Editora Nacional, traz boas fotografias e boas reproduções, embora não necessariamente um livro de história da arte brasileira para crianças, seu caráter didático, o dinamismo da leitura, podem ser úteis para uma apresentação conduzida por leitores adultos ou mesmo para atender a crianças maiores ${ }^{13}$.

Os livros de caráter mais geral de história da arte para crianças não são muitos. No que se refere à arte brasileira, são especialmente poucos. No entanto, são ainda mais raros os livros de períodos específicos da história da arte dedicados a pequenos leitores. Um exemplo isolado é O Impressionismo, um olhar mágico, em que uma viagem paródica explica o movimento, mostrando obras dos seus mais importantes pintores. Inclui, entre outros, um diálogo de Beaudelaire e biografias resumidas dos impressionistas ${ }^{14}$.

A Coleção Saber ver a arte, editada no Brasil pela Martins Fontes, da série espanhola Las Claves del Arte trazia volumes sobre a arte barroca, grega, mesopotâmica e persa, neoclássica, egípcia, etrusca e romana, gótica e românica. Embora não fosse dirigida ao público infantil, sua linguagem clara e concisa pode ser decifrada pelo professor e aplicada no âmbito de sala de aula. Explica certos conceitos e ajuda a visualizar as formas, ao abstrair certas obras em desenhos em preto e branco, com linhas vermelhas, elucidam a organização espacial ${ }^{15}$.

Em mesma medida, os livros que elegem um tema específico da história da arte para trazê-lo à criança, são também pouco numerosos como os que recortam um período específico da história. A série Minas Primeiras Descobertas da Arte de Claude Delafosse, pretende ser uma revelação aos olhos da criança através de filmes transparentes, apresentando com bom humor obras primas de todos os tempos. A proposta temática reúne obras de períodos diferentes. Apesar de pouco conteúdo, as reproduções das obras são manipuladas através de recursos óticos que ajudam a criança a observar os detalhes, a identificar fragmentos e, assim, ajudar na formação da memória visual. Estimula o pequeno leitor a ver as cores utilizadas pelo pintor, as variações de luz e de sombra. Possuem, os três títulos da série, Os

\footnotetext{
13 TIRAPELI, Percival. Arte Brasileira. 5 vol. São Paulo: Companhia Editora Nacional, 2006.

${ }^{14}$ BAILLET, Yolande. O Impressionismo, um olhar mágico. Ilustrações de Christian Maucler. Coleção Jardim dos Pintores. Rio de Janeiro, Salamandra, 1996.

15 CAPDEVILA, Juan. Org. Coleção Saber ver a Arte. São Paulo: Martins Fontes, 1991.
} 
Quadros, As Paisagens e Os Animais uma "galeria", onde a criança deve identificar fragmentos destacados de cada obra. Sugere-se, ao final, uma atividade de criação artística dentro do tema tratado ${ }^{16}$.

Também poderíamos agrupar com outras propostas de tratamento temático da história da arte para crianças o livro de Juliet Heslewood, História da Pintura Ocidental: Um Guia para Jovens. É uma obra muito bem pensada, pois articula temas da História, como Paz e Revolução ou Os Papas e a Realeza, e temas artísticos. As boas reproduções são comentadas como documentos históricos, as técnicas são explicadas, os personagens são apresentados. O texto é muito dinâmico, mas sua densidade talvez seja mais indicada a crianças maiores de dez anos ${ }^{17}$.

Podem ser considerados de abordagem temática e que tocam a história da arte os livros da irmã de caridade Wendy Beckett. Com grande sensibilidade, Meu primeiro livro de arte e oração, mais especificamente dirigido à leitura infantil, mas também sua série de Meditações são aproximações das obras de arte a partir de temas espirituais, como forma de elevação. Em suas palavras "contemplar a arte é um meio de ouvir a Deus". Seguindo seus próprios exercícios de meditação, como monja de clausura, Wendy Beckett propõe a crianças - a adultos também - um olhar de inspiração religiosa tanto sobre obras do passado quanto sobre inusitadas imagens contemporâneas ${ }^{18}$.

No entanto são muito mais correntes os livros de história da arte dirigidos às crianças, de caráter monográfico, sobretudo biografias de artistas. Parece ser a escolha mais freqüente dos autores que se dedicam a escrever livros infantis de história da arte. Entre tantos exemplos Michelangelo: Escultor, Pintor, Poeta conta quem foi o escultor florentino, narra seus primeiros anos; fala de Florença em tempos do Renascimento; do aprendizado do artista e de como se tornou um escultor. É não apenas

${ }^{16}$ DE LAFOSSE, Claude. Ilustrações de Tony Ross. Os Quadros.Gallimard Jeunesse. São Paulo, Melhoramentos, s/d. . As Paisagens. São Paulo: Melhoramentos, s/d. . Os Animais. São Paulo: Melhoramentos, s/d.

17 HESLEWOOD, Juliet. História da Pintura Ocidental: Um Guia para Jovens. Rio de Janeiro: Salamandra, 1994.

${ }^{18}$ BECKETT, Wendy. Meu primeiro livro de arte e oração. São Paulo: Manole, 1996. . Meditations on Joy. London, Dorling Kindersley Book, 1995. . Meditations on Silence. London, Dorling Kindersley Book, 1995. Meditations on Peace. London, Dorling Kindersley Book, 1995. Meditations on Love. London, Dorling Kindersley Book, 1995. 
uma biografia, mas uma análise simples de suas obras. É interessante também o capítulo que trata da restauração do teto da Capela Sistina ${ }^{19}$.

Uma solução curiosa de abordagem monográfica foi apresentada pela série Crianças Famosas: Picasso, Michelangelo ou Toulouse-Lautrec. Esta série apresenta leitura agradável e fácil, mostrando o dia a dia da infância de grandes artistas, o início de suas experiências no campo das artes, ilustrado também com reproduções de seus primeiros desenhos e obras juvenis. Os livros se encerram apontando as realizações do futuro daquelas crianças biografadas. A série funciona também como estímulo às crianças que gostam de desenhar e estão desenvolvendo atividades nas artes plásticas e na música (há também outros títulos de compositores célebres) ${ }^{20}$.

Da Coleção Jardim dos Pintores, Linéia no Jardim de Monet, a personagem Linéia narra, em primeira pessoa, sua visita ao jardim do pintor. Em Van Gogh, há uma biografia centrada na infância do pintor, e Mariana, a personagem de ficção, narra em primeira pessoa sua visita ao museu Kröller Müller, na Holanda. São mostrados objetos e lugares relacionados com a vida e a época do artista. Outro título desta coleção é Renoir, um eterno verão $\mathrm{O}^{21}$.

Entre as formas de apresentar biografias de artistas para crianças, a opção mais comum parece ser a de romancear ou revestir a vida e a obra de determinado artista de um sentido ficcional. Exemplo disso é a coleção Arte-Vida da editora Dimensão. Esta coleção conta com outros títulos não relacionados com artistas. Possui, talvez, mais um valor poético e literário do que propriamente historiográfico. As Duas Fridas é uma recriação do diário da pintora, com reproduções de sua obra e o significado biográfico e dramático de seus auto-retratos. O Carnaval de Arlequim é um texto literário que dialoga com um quadro de Miró, de mesmo título. O Inventor de Brincadeiras apresenta, com bom humor, a obra de Arcimboldo. Merece atenção Pérola-torta - um texto que combina ficção ou autobiografia - uma espécie de confissão do autor, um guia de turismo - e seu amor pela obra de

\footnotetext{
${ }^{19}$ RICHMOND, Robin. Michelangelo: Escultor, Pintor, Poeta. Rio de Janeiro: Salamandra, 1992.

${ }^{20}$ HART, Tony e HELLARD, Susan. Picasso. São Paulo: Callis, 1994. . Michelangelo. São Paulo, Callis, 1995. . Toulouse-Lautrec. São Paulo, Callis, 1995.

21 ANDERSON, Lima e BJORK, Christina. Linéia no Jardim de Monet. Rio de Janeiro: Salamandra, 1992.

LOUMAYE, Jacqueline. Van Gogh: um toque de amarelo. Ilustrações de Claudine Roucha. Rio de Janeiro: Salamandra, 1996.
} 
Aleijadinho. Traz uma biografia simplificada do escultor mineiro para a criança $^{22}$.

A propósito da apresentação monográfica de artistas brasileiros, há duas séries. Olharte e Mestres das Artes. Olharte, com livros sobre Goeldi e Picasso, traz também um volume sobre Tarsila do Amaral. Este livro é mais uma criação literária: um diálogo entre a neta e a avó, que foi amiga de infância, nos tempos da fazenda, de Tarsila do Amaral. Ao falar do passado, a avó explica, de modo muito simples, alguns dos elementos da obra e da biografia da pintora. O livrinho traz boas reproduções de quadros e desenhos de Tarsila ${ }^{23}$.

Também a Tarsila do Amaral e a Aleijadinho a Série Mestre das Artes dedica dois volumes. A coleção apresenta um caráter claramente paradidático, com imagens de obras de arte reproduzidas em lâminas de grande formato para serem usadas em sala de aula, além de uma série de exercícios a partir da leitura, com suplementos didáticos para professor e alunos. A receita é simples: adaptação da historiografia adulta para a linguagem infantil ${ }^{24}$.

Porém a idéia de transformar a vida e a obra de artistas em ficção para literatura infantil foi por vezes explorada de modo ainda mais inventivo. Uma incursão na obra do gravurista japonês Hokusai pode ser feita, por parte da criança, em $\mathrm{O}$ Velho louco por desenho, onde um menino vendedor de bolinhos de arroz se aproxima do mestre e se torna seu discípulo. São diálogos em que o mestre se recorda de seu passado. Procura-se transmitir a recriação do ambiente de uma oficina de gravuras no Japão do século XIX ${ }^{25}$.

Mas há ainda outro importante caminho de apresentação da história da arte para crianças. Trata-se dos guias de exposições, de museus ou mesmo dos guias de viagem para crianças. Sobre guias de exposições de arte, podemos recordar dois exemplos. O primeiro é O Toque Revelador:

22 AGOSTINHO, Cristina. As duas Fridas. Coleção Arte-Vida.Belo Horizonte, Dimensão, 1995 ROCHAEL, Denise. O Carnaval de Arlequim. Coleção Arte-Vida. Belo Horizonte: Dimensão, 1995 CUNHA, Leo. O Inventor de Brincadeiras. Coleção Arte-Vida. Belo Horizonte: Dimensão, 1995 COELHO, Simões. Pérola-torta. Coleção Arte-Vida. Belo Horizonte: Dimensão, 1995

${ }^{23}$ TEIXEIRA, Zéflavio e ZATZ, Lia. Tarsila. Série OlhArte. São Paulo: USP-MAC, Paulinas, 1995.

${ }^{24}$ BRAGA, Ângela e REGO, Lígia. Tarsila do Amaral. Mestres das Artes no Brasil. São Paulo: Moderna, 1999.

São Paulo: Moderna, 1999. Antônio Francisco Lisboa, o Aleijadinho. Mestres das Artes no Brasil.

${ }^{25}$ PLACE, François. O Velho louco por desenho. São Paulo: Companhia das Letrinhas, 2004. 
retratos e auto-retratos. Esta edição era uma apostila em fotocópia que servia de guia à exposição de mesmo título. A exposição, de março de 1997 no anexo do Museu de Arte Contemporânea da Universidade de São Paulo, era dirigida a deficientes visuais, através de uma pesquisa de transformar a obra visual em uma forma tátil (em relevo). Era também dirigida às crianças, pois ao lado havia uma sala de brincadeiras, com jogos relacionados às imagens da exposição (quebra-cabeça, dominó, mico, feitos de madeira com reproduções em fotocópia coladas), além de fantasias e um grande espelho para a criança inventar seu próprio retrato. A publicação, voltada à criança, trazia uma explicação sobre a arte do retrato e as biografias dos pintores apresentados, além de uma análise muito simples do retrato respectivo ${ }^{26}$.

O segundo exemplo, com texto de Elisabetta Puttini, distribuído como fotocópia: Un interessante esperimento dedicato ai bambini "Intorno a Poussin" da exposição realizada na Galeria Nazionale d'Arte Antica, em Roma, entre novembro de 1994 e janeiro de 1995. Uma simpática personagem de nome Alice guia as crianças e ensina, através de brincadeiras, a apreciar uma exposição de pinturas. A idéia de "caça ao tesouro", de identificação de fragmentos e elementos das obras e as pontuações funciona como um estímulo para o olhar ${ }^{27}$.

Um procedimento semelhante e com participação da mesma autora foi adotado para guiar as crianças ao Museu Egípcio do Vaticano. Alice nei Musei delle Meraviglie. Scopri con me il Museo Gregoriano Egizio in Vaticano traz uma primeira parte sobre a vida no Egito Antigo. Mais interessante, porém, é a segunda parte, onde Alice, a mesma menina de doze anos, guia os pequenos visitantes, para que descubram as peças no museu. A metodologia é interessante: numa espécie de "caça ao tesouro", com pontos que vão sendo somados, as crianças vão aprendendo a observar a arte com mais atenção ${ }^{28}$.

O Ministero per i Beni e le Attività Culturali, na Itália, dentro do programa "Crianças ao Museu: os domingos de arte", publicou entre outros materiais, uma caderneta de anotações, em 2001, para guiar atividades

\footnotetext{
${ }^{26}$ MAC- USP Anexo. O Toque Revelador: retratos e auto-retratos. Março, 1997.

27 PUTINI, Elisabetta. Un interessante esperimento dedicato ai bambini "Intorno a Poussin". Galeria Nazionale d'Arte Antica. Roma : Nov.1994 a Gen. 1995.

${ }^{28}$ BACCANI, Constanza e PUTINI, Elisabetta. Alice nei Musei delle Meraviglie. Scopri con me il Museo Gregoriano Egizio in Vaticano. Edizioni Musei Vatcani, 1996
} 
infantis, adaptável a diferentes museus italianos. Contendo uma carteira de identificação de investigador de um tal departamento de crimes de arte para que cada criança inventasse, ao visitar um museu, um crime que deveria ser investigado ${ }^{29}$.

Além de guiar o olhar infantil por exposições e museus, alguns projetos editoriais dedicaram-se a guias de viagem, onde a cidade era visitada em suas obras de arte. I Bambini alla Esoperta da Castel Sant'Angelo a San Pietro fazia parte de um projeto de publicações de guias infantis que se estendia a Roma Antiga e a outras cidades italianas. De modo divertido, o guia propõe uma visita à cidade, dirigindo o olhar da criança aos monumentos, estilos, artistas que trabalharam nestas obras. Foi escrito para ser consultado durante os passeios pela cidade, como um mapa que conduz aos "tesouros" artísticos que a cidade guarda - revelando as obras e sua história. Além de descrever e explicar os monumentos, o livro propõe jogos, como nos exemplo anteriores, onde a criança deve encontrar certos elementos e identificar formas durante o passeio. Ao final temos algumas biografias de homens célebres do período, incluindo de alguns $\operatorname{artistas}^{30}$.

Nos limites desse texto, procurou-se agrupar, de modo provisório, alguns livros de história da arte para crianças, editados sobretudo no Brasil, do seguinte modo: aqueles que, embora não sejam propriamente de história da arte, apresentam aspectos técnicos da criação artística; as publicações de caráter lúdico, que familiarizam o olhar infantil com obras de arte, através de jogos e brincadeiras; os livros gerais de história da arte e de história da arte brasileira; os que abordam um período específico da história da arte; os livros temáticos, ou seja, que elegem um tema e agrupam obras de diferentes períodos; as biografias de artistas, que se dividem entre as monografias historiográficas e as biografias romanceadas; e, por fim, os guias de exposições, de museus e de viagem.

A organização de uma pequena biblioteca de história da arte para crianças, assim como de qualquer biblioteca, é uma tarefa sem fim. A classificação de livros poderia ser feita de outras e infinitas maneiras como sempre nos ensinou Jorge Luiz Borges. Um quadro incompleto

${ }^{29}$ DALlari, M.; CARATINI, A. e PINELLI, S. Bambini al Museo Le Dominche di Art'E' operazione (nome in codice). Bologna : Ministero per i Beni e le Attività Culturali, 2001.

${ }^{30}$ CARRELLI, Vannella e PUNZI, Rosaria. I Bambini alla Esoperta da Castel Sant'Angelo a San Pietro. Roma: Fratelli Palombi, 1997. 
composto de edições de história da arte para crianças forma um quebracabeça de peças desiguais. As abordagens são diversas, e muitas são as lacunas.

\section{Bibliografia}

AGOSTINHO, Cristina. As duas Fridas. Coleção Arte-Vida.Belo Horizonte, Dimensão, 1995

ANDERSON, Lima e BJORK, Christina. Linéia no Jardim de Monet. Rio de Janeiro: Salamandra, 1992.

BACCANI, Constanza e PUTINI, Elisabetta. Alice nei Musei delle Meraviglie. Scopri con me il Museo Gregoriano Egizio in Vaticano. Edizioni Musei Vatcani, 1996

BAILLET, Yolande. O Impressionismo, um olhar mágico. Ilustrações de Christian Maucler. Coleção Jardim dos Pintores. Rio de Janeiro, Salamandra, 1996.

BECKETT, Wendy. Meditations on Joy. London, Dorling Kindersley Book, 1995.

BECKETT, Wendy. Meditations on Love. London, Dorling Kindersley Book, 1995.

BECKETT, Wendy. Meditations on Peace. London, Dorling Kindersley Book, 1995.

BECKETT, Wendy. Meditations on Silence. London, Dorling Kindersley Book, 1995.

BECKETT, Wendy. Meu primeiro livro de arte e oraşão. São Paulo: Manole, 1996.

BRAGA, Angela e REGO, Lígia. Antônio Francisco Lisboa, o Aleijadinho. Mestres das Artes no Brasil. São Paulo: Moderna, 1999.

BRAGA, Ângela e REGO, Lígia. Tarsila do Amaral. Mestres das Artes no Brasil. São Paulo: Moderna, 1999.

CAPDEVILA, Juan. Org. Coleção Saber ver a Arte. São Paulo: Martins Fontes, 1991.

CARRELLI, Vannella e PUNZI, Rosaria. I Bambini alla Esoperta da Castel Sant'Angelo a San Pietro. Roma: Fratelli Palombi, 1997.

COELHO, Simões. Pérola-torta. Coleção Arte-Vida. Belo Horizonte: Dimensão, 1995

CUMMING, Robert. Para entender a arte. São Paulo: Ática, 1996.

CUNHA, Leo. O Inventor de Brincadeiras. Coleção Arte-Vida. Belo Horizonte: Dimensão, 1995

DALLARI, M.; CARATINI, A. e PINELLI, S. Bambini al Museo Le Dominche di Art'E' operazione (nome in codice). Bologna : Ministero per i Beni e le Attività Culturali, 2001.

DE LAFOSSE, Claude. As Paisagens. São Paulo: Melhoramentos,s/d.

DE LAFOSSE, Claude. Ilustrações de Tony Ross. Os Quadros.Gallimard Jeunesse. São Paulo, Melhoramentos, s/d.

DE LAFOSSE, Claude. Os Animais. São Paulo: Melhoramentos, s/d.

Encyclopedia pela Imagem. Porto: Lello \& Irmãos, s.d.

Era uma vez. o cinema. São Paulo: Melhoramentos, s/d.

FIGUEIREDO, Lenita Miranda de. História da Arte para Crianças. São Paulo: Pioneira, 1982.

GIRARDET, Sylvie. et allii. A arte de Leonardo. São Paulo: Cia das Letrinhas, 1997.

GIRARDET, Sylvie. Giotto pintor de paredes. São Paulo: Cia das Letrinhas, 1997.

GORDINHO, Margarida Cintra et al. Gráfica: Arte e Indústria no Brasil: 180 anos de bistória. São Paulo: Bandeirante, 1991.

HART, Tony e HELLARD, Susan. Michelangelo. São Paulo, Callis, 1995.

HART, Tony e HELLARD, Susan. Picasso. São Paulo: Callis, 1994. 
HART, Tony e HELLARD, Susan. Toulouse-Lautrec. São Paulo, Callis, 1995.

HESLEWOOD, Juliet. História da Pintura Ocidental: Um Guia para Jovens. Rio de Janeiro: Salamandra, 1994.

HOLT, Rod. Pintura a Óleo: Estojo de Trabalho. Blumenau, Eko, 1997.

JAMES, John e MACDONALD, Fiona. Uma Catedral Medieval. São Paulo: Massole, 1993. Coleção Fique por dentro da História.

JANUSZCZAK, Waldemar e McCLEERY, Jenny. Compreender a Arte. Lisboa/São Paulo: Verbo Juvenil, 1984.

LOUMAYE, Jacqueline. Van Gogh: um toque de amarelo. Ilustrações de Claudine Roucha. Rio de Janeiro: Salamandra, 1996.

MAC- USP Anexo. O Toque Revelador: retratos e auto-retratos. Março, 1997.

MANGE, Marilyn Diggs. Arte Brasileira para Crianças. São Paulo: Martins Fontes, 1996.

MICKELETHWAIT, Lucy. Para a criança brincar com arte. O prazer de explorar belas pinturas. São Paulo: Ática, 1997.

PAULA, Ademar A. de e CARRAMILLO NETO, Mário. Artes Gráficas no Brasil. Registros: 1746-1941

PLACE, François. O Velho louco por desenho. São Paulo: Companhia das Letrinhas, 2004.

PUTINI, Elisabetta. Un interessante esperimento dedicato ai bambini "Intorno a Poussin". Galeria Nazionale d'Arte Antica. Roma: Nov.1994 a Gen. 1995.

RICHMOND, Robin. Michelangelo: Escultor, Pintor, Poeta. Rio de Janeiro: Salamandra, 1992.

ROCHAEL, Denise. O Carnaval de Arlequim. Coleção Arte-Vida. Belo Horizonte: Dimensão, 1995

TEIXEIRA, Zéflavio e ZATZ, Lia. Tarsila. Série OlhArte. São Paulo: USP-MAC, Paulinas, 1995.

TIRAPELI, Percival. Arte Brasileira. 5 vol. São Paulo: Companhia Editora Nacional, 2006.

VAN DER MEER, Ron e WHITFORD, Frank. Uma Iniciação Interativa às Artes Plásticas. No Mundo da Arte. 